\title{
Effect of Rib Flexibility on the Vibration Modes of a Delta-Wing Aircraft
}

\author{
Wilhelmina D. Kroll
}

\begin{abstract}
A systematic study was made to determine whether decreasing the number of ribs or making the ribs more flexible would have any appreciable effect on the vibration modes and frequencies of a delta-wing aircraft. The modes and frequencies were computed for the basic wing and for the following modifications of the basic wing: (1) One rib outboard of the fuselage removed, (2) two ribs removed, (3) stiffness of ribs outboard of fuselage reduced one-half, and (4) rib stiffness reduced nine-tenths. The results indicated that the frequencies and mode shapes of the modified wings differed little from those of the basic wing and, therefore, that changes similar to these modifications would not appreciably affect the vibration characteristics of delta wings.
\end{abstract}

\section{Introduction}

The designer of an airplane might eliminate some of the wing ribs or reduce their stiffnesses if he were faced with the problem of providing room for fuel tanks or other stores in the airplane wing or of making the wing thinner for flight at higher speeds. As a result of these structural modifications, the airplane wings during flight might be subject to chordwise bending with attendant changes in the modes and frequencies of the wing vibration.

An experimental investigation on model wings was carried out at the Southwest Research Institute to determine the effect of chordwise bending on the flutter characteristics of several shapes of wings [1]. ${ }^{1}$ The models were low-aspect ratio cantilever wings having wing-bending, wing-torsion, and rib-bending degrees of freedom. The bending and torsion stiffnesses of the wings were kept fixed but the rib stiffnesses were reduced by cutting the main ribs at three chordwise stations and then reconnecting adjacent sections of the ribs with steel beam-type springs of specified stiffnesses. The critical flutter speeds of the wings for four different values of rib stiffness were obtained in a wind tunnel at subsonic speeds. One of the conclusions from this study was that decreasing the rib-bending stiffness of an airplane wing consistently decreases its critical flutter speed. The reduction in critical flutter speed was 13 percent of the rigid rib condition for the delta wing, 22 percent for the 45 degree sweptback wing, and 40 percent for the straight wing.

This experimental work led to the present investigation in which the purpose was to determine if the computed natural modes and frequencies of airplanes which differ in chordwise stiffness would indicate that one might expect a reduction of critical flutter speed for full-scale airplanes similar to the reduction found in the model experiments. No flutter analyses were made.

As the trend for high-speed, low-aspect ratio, thin wings is toward the delta shape, a delta-wing airplane was used for this study. The vibration modes and frequencies of the airplane were computed. The wing structure was then modified so as to differ from

\footnotetext{
1 Figures in brackets indicate the literature references at the end of this paper.
}

the original in having lower chordwise stiffnesses. These modifications were: (1) One rib outboard of fuselage removed, (2) two ribs outboard of fuselage removed, (3) stiffnesses of ribs outboard of fuselage reduced one-half, and (4) rib stiffness reduced ninetenths. The frequencies and modes of vibration of these modified wings were also computed.

This work was done at the National Bureau of Standards under the sponsorship and with the financial assistance of the Bureau of Aeronautics, Department of the Navy.

\section{Structure}

The airplane chosen for this study had a delta wing with 6 spars and 12 ribs, figure 1 . The actual structure was simplified, for ease of computation, into the structure of figure 2 which had the same number of spars but only 5 ribs. The moments of inertia of the 5 composite ribs were equal to those of the 12 ribs in the actual structure. The simplified structure had, therefore, the same torsional and bending properties as the original one. Rib 5 was on the centerline of the airplane, rib 4 was at the junction of the wing and the fuselage and ribs 1,2 , and 3 were all outboard of the fuselage. The locations of the spars and composite ribs are shown in figure 2 .

The following four modifications of the wing which would result in the wing having less chordwise stiffness were considered:

\section{Case A.1 Rib 2 removed from wing.}

Case A.2 Ribs 1 and 3 removed from wing.

Case B.1 Stiffnesses of ribs 1, 2, and 3 reduced to half their original values.

Case B.2 Stiffnesses of ribs 1, 2, and 3 reduced to one-tenth their original values.

These modified wings are shown in figure 3.

\section{Influence Coefficients}

The method of obtaining the influence coefficient matrix of the wing is described in reference [2]. It is a method of consistent deformations. The total load carried by the wing is considered to be the sum 


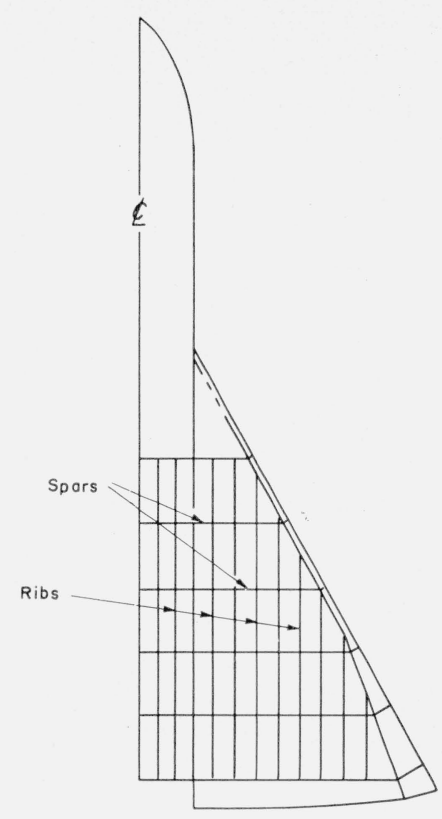

Figure 1. Structure of delta-wing airplane.

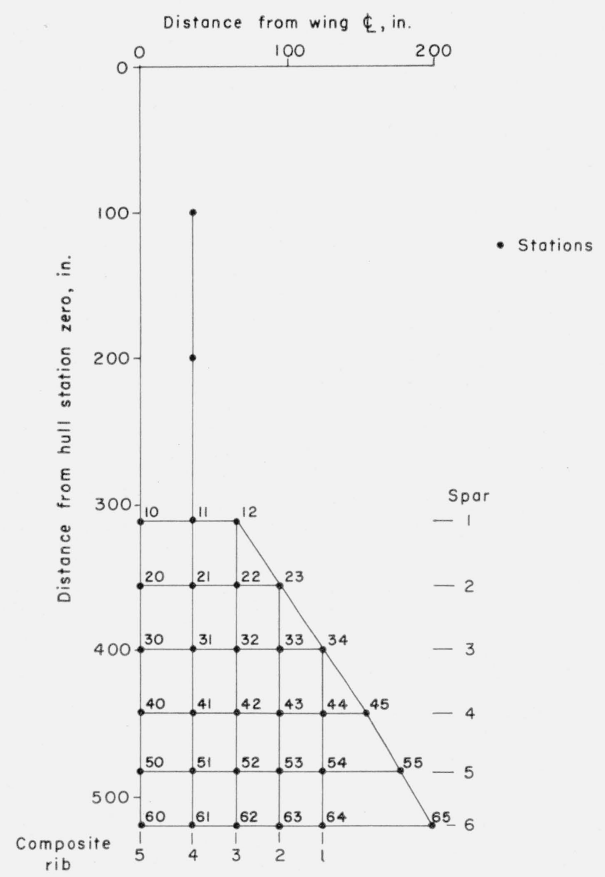

FIGURE 2. Location of stations on the wing and fuselage of simplified structure.

of the loads carried (1) by the spars in bending, (2) by the ribs in bending, and (3) by the cover sheet in torsion.

In computing the influence coefficients, the following conditions were used:

(1) The station at the junction of rib 5 and spar 6 , station 60 , was clamped.

(2) The leading edge of the wing had no bending stiffness.
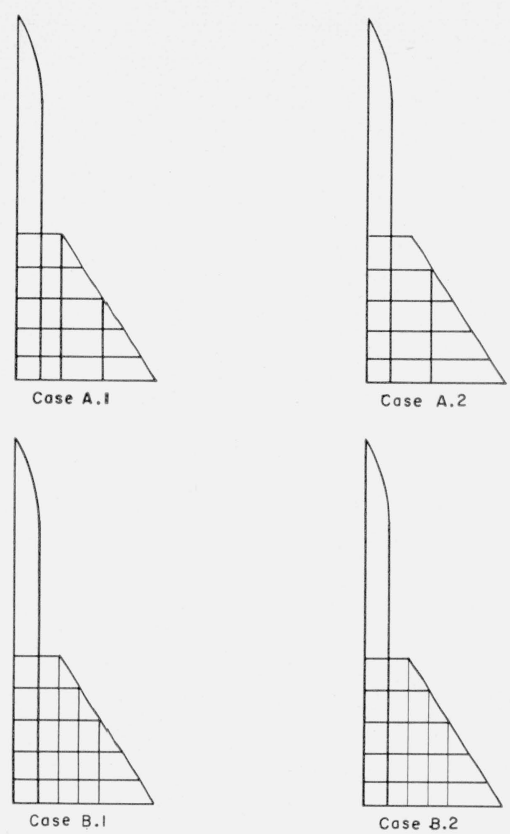

Figure 3. Modifications of basic wing.

Case A.1, Rib 2 removed from wing; Case A.2, ribs 1 and 3 removed from wing, Case B. 1 , bending stiffiness of ribs 1,2 , and 3 reduced to one-half their original stiffness; Case B.2, bending stiffiness of ribs 1,2 , and 3 reduced to one-tenth their original stiffness.

(3) The spars extended to the leading edge. The moment of inertia of a spar at the leading edge was zero, condition (2), but was taken arbitrarily as 3.5 in. ${ }^{4}$ so that influence coefficients for stations on the leading edge could be computed. This value of 3.5 in. ${ }^{4}$ is small compared to moments of inertia at other stations along the spar.

(4) Half of the fuselage stiffness was added to the stiffness of rib 4 in computing the influence coefficient matrix for symmetric modes.

(5) One-tenth of the fuselage stiffness was added to the stiffness of rib 4 , and the torsional stiffnesses of the torque boxes between ribs 4 and 5 were increased by a factor of 10 in computing the matrix for the antisymmetric modes.

(6) For the torsion boxes, the triangular segments of the wing form part of the adjacent rectangular boxes.

\subsection{Influence Coefficients for Unmodified Wing}

The influence coefficient matrix for the symmetric case gives the deflection at point $n$ due to a unit upload at point $m$ on both sides of the wing when station 60 is clamped. The influence coefficient matrix for the antisymmetric case gives the deflection at point $n$ due to a unit up-load at point $m$ on the left half of the wing and a unit down-load at point $m$ on the right half of the wing with station 60 clamped. Therefore, the deflections of the wing as given by the influence coefficient matrix are those obtained by subtracting from the wing deflection at the various stations the deflection of a plane tangent to the wing at station 60 . 
For the symmetric modes, the reference plane for the deflections has displacement and pitch but no roll. The slope of the reference plane normal to the fuselage axis must be zero along the fuselage axis.

The influence coefficients were computed by SEAC, Standards Eastern Automatic Computer, for each of the spars and ribs considering the root stations clamped. The method used is explained in [3]. The root stations for the spars were along the fuselage axis and those for the ribs along spar 6, figure 2. For spars 1 to 5 , the root stations can be displaced but the slopes at those stations are zero due to the svmmetrical loads on the other half of the wing. In matrix notation, for spars 1 to 5 , the computation above yields

$$
\left\{y-y_{\imath}\right\}=[\delta]\{L\}
$$

where

$\left\{y-y_{t}\right\}$ is the matrix of deflections at all stations but the root station $t$,

$[\delta]$ is the matrix of influence coefficients considering the root station clamped,

$\{L\}$ is the load matrix for all stations but the root station $t$.

For spar 1, for example, the following matrix using the data of table 1 was obtained

$$
\left\{\begin{array}{l}
y_{11}-y_{10} \\
y_{12}-y_{10}
\end{array}\right\}=\left[\begin{array}{rr}
0.0000198943 & 0.0000444295 \\
.0000444295 & .0001295786
\end{array}\right]\left\{\begin{array}{l}
L_{11} \\
L_{12}
\end{array}\right\}
$$

To obtain the loads in terms of the deflections, from. (1),

$$
\{L\}=[\delta]^{-1}\left\{y-y_{t}\right\}
$$

where $[\delta]^{-1}$ is the inverse of $[\delta]$. This is eq (11a), [2]

TABLE 1.-Data needed to determine influence coefficients of spar 1

\begin{tabular}{|c|c|c|}
\hline Station & $\begin{array}{c}\text { Distance } \\
\text { from rib 5 }\end{array}$ & $\begin{array}{c}\text { Moment of } \\
\text { inertia }\end{array}$ \\
\cline { 2 - 3 } 10 & in. & in.4 \\
10 & 0 & 124.55 \\
$\mathrm{a}$ & 7 & 112.00 \\
$\mathrm{~b}$ & 14 & 100.80 \\
$\mathrm{c}$ & 21 & 90.20 \\
$\mathrm{~d}$ & 28 & 79.80 \\
$\mathrm{11}$ & 35 & 69.04 \\
$\mathrm{e}$ & 42 & 59.40 \\
$\mathrm{f}$ & 49 & 49.50 \\
$\mathrm{~g}$ & 56 & 39.49 \\
$\mathrm{~h}$ & 63 & 29.70 \\
12 & 65 & 25.00 \\
\hline
\end{tabular}

For spar 1, from (1a),

$$
\begin{aligned}
& \left\{\begin{array}{l}
L_{11} \\
L_{12}
\end{array}\right\}=\left[\begin{array}{crc}
251275 & -145955.4 \\
-145955.4 & 175689.7
\end{array}\right]\left\{\begin{array}{l}
y_{11}-y_{10} \\
y_{12}-y_{10}
\end{array}\right\} \\
& =\left[\begin{array}{lrr}
251275 & -145955.4 & -105320 \\
145955.4 & 175689.7 & -29734.3
\end{array}\right]\left\{\begin{array}{l}
y_{11} \\
y_{12} \\
y_{10}
\end{array}\right\} .
\end{aligned}
$$

However, in symmetric motion, the sum of the vertical forces is equal to zero, or

$$
L_{i}=-L_{r}-L_{s}-\ldots-L_{j} \ldots-L_{n}
$$

where the subscript $t$ refers to the root station and other subscripts to the other stations along the spars. Applying this to eq (2a) for spar 1, the loads at all the stations on spar 1 in terms of the deflections at those stations for a root condition of free displacement, zero root slope, are

$$
\begin{aligned}
& \left\{\begin{array}{l}
L_{11} \\
L_{12} \\
L_{10}
\end{array}\right\} \\
& =\left[\begin{array}{crc}
251275 & -145955.4 & -105320 \\
-145955.4 & 175689.7 & -29734.3 \\
-105320 & -29734.3 & 135054
\end{array}\right]\left\{\begin{array}{l}
y_{11} \\
y_{12} \\
y_{10}
\end{array}\right\} .
\end{aligned}
$$

The loads for spars $2,3,4$, and 5 were obtained in a similar manner. The loads in spar 6 and in rib 5 were obtained by using eq (2b), reference [2], which is applicable for a clamped root condition. Equations (11) and (12), reference [2], were used to determine the loads in ribs 1 to 4 with free root conditions.

The loads carried by the individual torsion boxes were computed according to the method outlined in reference [2].

The deflections equivalent to the loads carried by the spars, ribs and torsion boxes were summed to give the external load carried by the composite wing. The matrix relating the external loads to the deflections, or the composite stiffness matrix, was then inverted to give the symmetric influence coefficient matrix for the wing.

\section{b. Influence Coefficients for Antisymmetric Modes}

For the wing in antisymmetric vibration, the airplane will have roll but no pitch or displacement relative to a plane tangent to the airplane wing at station 60 . This would mean that the fuselage axis could rotate but not deflect, and, therefore, the deflections at stations along the fuselage axis would be zero.

As in the case for symmetric modes, the influence coefficients, considering the root clamped, were computed for the ribs and spars by the method of reference [3]. The loads carried by spars 1 to 5 were obtained by use of eq (10), reference [2], for a simplysupported root condition; the loads carried by spar 
6 were given by eq (2b), reference [2], for a clamped root condition; and the loads carried by ribs 1 to 4 were given by eqs (11) and (12), reference [2], for a free root condition. No computations were made for rib 5 because rib 5 is along the fuselage axis and, as stated above, the deflections would be zero.

The loads carried by the individual torsion boxes were computed as outlined in reference [2].

The composite stiffness matrix for antisymmetrical vibration, obtained by summing the deflections equivalent to the loads carried by the spars, ribs, and torsion boxes at the various wing stations, was inverted to give the antisymmetric influence coefficient matrix.

\subsection{Influence Coefficients for Wings With Ribs Removed}

Two different configurations of the wing with fewer ribs than the basic wing were investigated. In case A.1, rib 2 was removed and in case A.2, ribs 1 and 3 were removed. It was assumed, in computing the influence coefficients, that shear webs were present to transmit shear at the locations of the removed ribs but that these shear webs contributed nothing to the bending stiffness of the wing. It is believed that this assumption would not cause large errors in the results.

The composite stiffness matrix for case A.1 was obtained by summing the deflections equivalent to the loads carried by the spars, by ribs $1,3,4$, and 5 , and by the torsion boxes.

The composite stiffness matrix for case A.2 was obtained by summing the deflections equivalent to the loads carried by the spars, by ribs 2,4 , and 5 , and by the torsion boxes.

The composite stiffness matrices were inverted to give the influence coefficient matrices.

\subsection{Influence Coefficients for Wings With Reduced Flexibility}

In order to study the effect of reduced rib flexibility of the entire wing outboard of the fuselage on the vibration characteristics of the airplane, the ribs in that region were considered to have one-half of their original stiffness in case B.1 and one-tenth of their original stiffness in case B.2. The composite stiffness matrices differed from those for the basic wing by having the deflections equivalent to the loads carried by ribs 1,2 , and 3 reduced by 50 percent in case B.1 and by 90 percent in case B.2. The influence coefficient matrices were obtained by inverting these stiffness matrices.

\section{Modes of Vibration}

The modes and frequencies of the airplanes were computed by SEAC. The method of computation and the codes written to do this work on SEAC are described in reference [4]. The masses at stations along the fuselage axis were considered lumped with those on rib 4 which is at the junction of the wing and fuselage. The locations of the stations and the
TABLE 2. Masses at stations and location of stations.

\begin{tabular}{|c|c|c|c|}
\hline Station & Mass & $\begin{array}{l}\text { Spanwise } \\
\text { location } \\
x\end{array}$ & $\begin{array}{c}\text { Chordwise } \\
\text { location } \\
z\end{array}$ \\
\hline $\begin{array}{l}61 \\
62 \\
63 \\
64 \\
65\end{array}$ & $\begin{array}{r}l b \text { sec }^{2} / \mathrm{in} \text {. } \\
3.79503 \\
0.14034 \\
.14195 \\
.32369 \\
.18343\end{array}$ & $\begin{array}{c}\text { in. } \\
35 \\
65 \\
95 \\
125 \\
198.6\end{array}$ & in. \\
\hline $\begin{array}{l}50 \\
51 \\
52 \\
53 \\
54 \\
55\end{array}$ & $\begin{array}{r}0 \\
3.71553 \\
0.12099 \\
.12093 \\
.12707 \\
.16938\end{array}$ & $\begin{array}{c}0 \\
35 \\
65 \\
95 \\
125 \\
177.1\end{array}$ & 37 \\
\hline $\begin{array}{l}40 \\
41 \\
42 \\
43 \\
44 \\
45\end{array}$ & $\begin{array}{r}0 \\
2.82958 \\
0.31897 \\
.29490 \\
.15024 \\
.05325\end{array}$ & $\begin{array}{c}0 \\
35 \\
65 \\
95 \\
125 \\
154.1\end{array}$ & 77 \\
\hline $\begin{array}{l}30 \\
31 \\
32 \\
33 \\
34\end{array}$ & $\begin{array}{r}0 \\
1.38148 \\
0.50266 \\
.37260 \\
.08068\end{array}$ & $\begin{array}{r}0 \\
35 \\
65 \\
95 \\
125\end{array}$ & 121 \\
\hline $\begin{array}{l}20 \\
21 \\
22 \\
23\end{array}$ & $\begin{array}{r}0 \\
1.61046 \\
0.48945 \\
.15619\end{array}$ & $\begin{array}{r}0 \\
35 \\
65 \\
95\end{array}$ & 165 \\
\hline $\begin{array}{l}10 \\
11 \\
12\end{array}$ & $\begin{array}{r}0 \\
\text { 4. } 55061 \\
0.26255\end{array}$ & $\begin{array}{r}0 \\
35 \\
65\end{array}$ & $\stackrel{209}{\downarrow}$ \\
\hline $\begin{array}{l}02 \\
01\end{array}$ & $\begin{array}{l}\text { 2. } 34865 \\
\text { 3. } 26669\end{array}$ & $\begin{array}{l}35 \\
35\end{array}$ & $\begin{array}{l}320 \\
420\end{array}$ \\
\hline
\end{tabular}

masses at the stations are given in table 2. These, together with the composite influence coefficient matrices, were used in the computation.

The frequencies of the symmetric and antisymmetric modes of vibration of the basic wing and of the four modified wings are given in table 3 . The nodal lines and relative displacements of parts of the airplane wing and fuselage are shown in figure 4 for the symmetric modes of vibration and in figure 5 for the antisymmetric ones. In a particular mode of vibration, the cross-hatched parts of the airplane would be deflected downward and the other parts upward, or vice versa.

The normalized deflections of the wing in the symmetric and antisymmetric modes for case B.1, wing-rib stiffness 50 percent of original stiffness, are plotted in figure 6 . The dotted lines indicate negative deflections of the wing and the solid lines, positive deflections. These are typical of the results obtained in the other cases. The values of the deflections for the symmetric case are given in table 4 .

\section{Results and Discussion}

The ratios of the frequencies for the modified wings to those of the basic wing were computed and are given in table 5. It is seen from the values of the ratios that, for the first three modes of symmetric and antisymmetric vibration, the frequencies of the modified wings are within 2 percent of the frequencies for the unmodified wing. In the fourth symmetric mode, however, the frequency for case A.2, two ribs 
TABLE 3. Natural frequencies of wings

\begin{tabular}{|c|c|c|c|c|c|c|c|c|c|c|}
\hline Mode_- & \multicolumn{2}{|c|}{1} & \multicolumn{2}{|c|}{2} & \multicolumn{2}{|c|}{3} & \multicolumn{2}{|c|}{4} & \multicolumn{2}{|c|}{5} \\
\hline Case & $\mathrm{rad} / \mathrm{sec}$ & cps & $\mathrm{rad} / \mathrm{sec}$ & cps & $\mathrm{rad} / \mathrm{sec}$ & cps & $\mathrm{rad} / \mathrm{sec}$ & cps & $\mathrm{rad} / \mathrm{sec}$ & cps \\
\hline \multicolumn{11}{|c|}{ SYMMETRIC } \\
\hline $\begin{array}{l}\text { Basic } \\
\text { A.1 } \\
\text { A.2 } \\
\text { B.1 } \\
\text { B.2 }\end{array}$ & $\begin{array}{l}48.78 \\
48.29 \\
48.28 \\
48.34 \\
47.86\end{array}$ & $\begin{array}{l}7.76 \\
7.69 \\
7.68 \\
7.69 \\
7.62\end{array}$ & $\begin{array}{l}69.14 \\
68.71 \\
68.59 \\
68.65 \\
68.56\end{array}$ & $\begin{array}{l}11.00 \\
10.94 \\
10.92 \\
10.93 \\
10.91\end{array}$ & $\begin{array}{l}133.90 \\
133.24 \\
133.01 \\
133.41 \\
131.89\end{array}$ & $\begin{array}{l}21.31 \\
21.21 \\
21.17 \\
21.23 \\
20.99\end{array}$ & $\begin{array}{l}168.68 \\
159.51 \\
142.42 \\
152.95 \\
135.72\end{array}$ & $\begin{array}{l}26.85 \\
25.39 \\
22.67 \\
24.34 \\
21.60\end{array}$ & $\begin{array}{l}185.34 \\
181.07 \\
183.37 \\
179.88\end{array}$ & $\begin{array}{l}29.50 \\
28.82 \\
29.18 \\
28.63\end{array}$ \\
\hline \multicolumn{11}{|c|}{ ANTISYMMETRIC } \\
\hline $\begin{array}{l}\text { Basic_. } \\
\text { A.1_-. } \\
\text { A.2-. } \\
\text { B.1_- } \\
\text { B.2_- }\end{array}$ & $\begin{array}{l}19.36 \\
19.36 \\
19.34 \\
19.35 \\
19.34\end{array}$ & $\begin{array}{l}3.08 \\
3.08 \\
3.08 \\
3.08 \\
3.08\end{array}$ & $\begin{array}{l}58.08 \\
57.77 \\
57.43 \\
57.66 \\
57.12\end{array}$ & $\begin{array}{l}9.24 \\
9.19 \\
9.14 \\
9.18 \\
9.09\end{array}$ & $\begin{array}{l}97.67 \\
97.59 \\
97.40 \\
97.50 \\
97.30\end{array}$ & $\begin{array}{l}15.54 \\
15.53 \\
15.50 \\
15.52 \\
15.49\end{array}$ & $\begin{array}{l}120.41 \\
119.44 \\
117.84 \\
118.86 \\
116.53\end{array}$ & $\begin{array}{l}19.16 \\
19.01 \\
18.75 \\
18.92 \\
18.55\end{array}$ & $\begin{array}{l}151.33 \\
150.85 \\
144.91 \\
149.54 \\
141.44\end{array}$ & $\begin{array}{l}24.08 \\
24.01 \\
23.06 \\
23.80 \\
22.51\end{array}$ \\
\hline
\end{tabular}
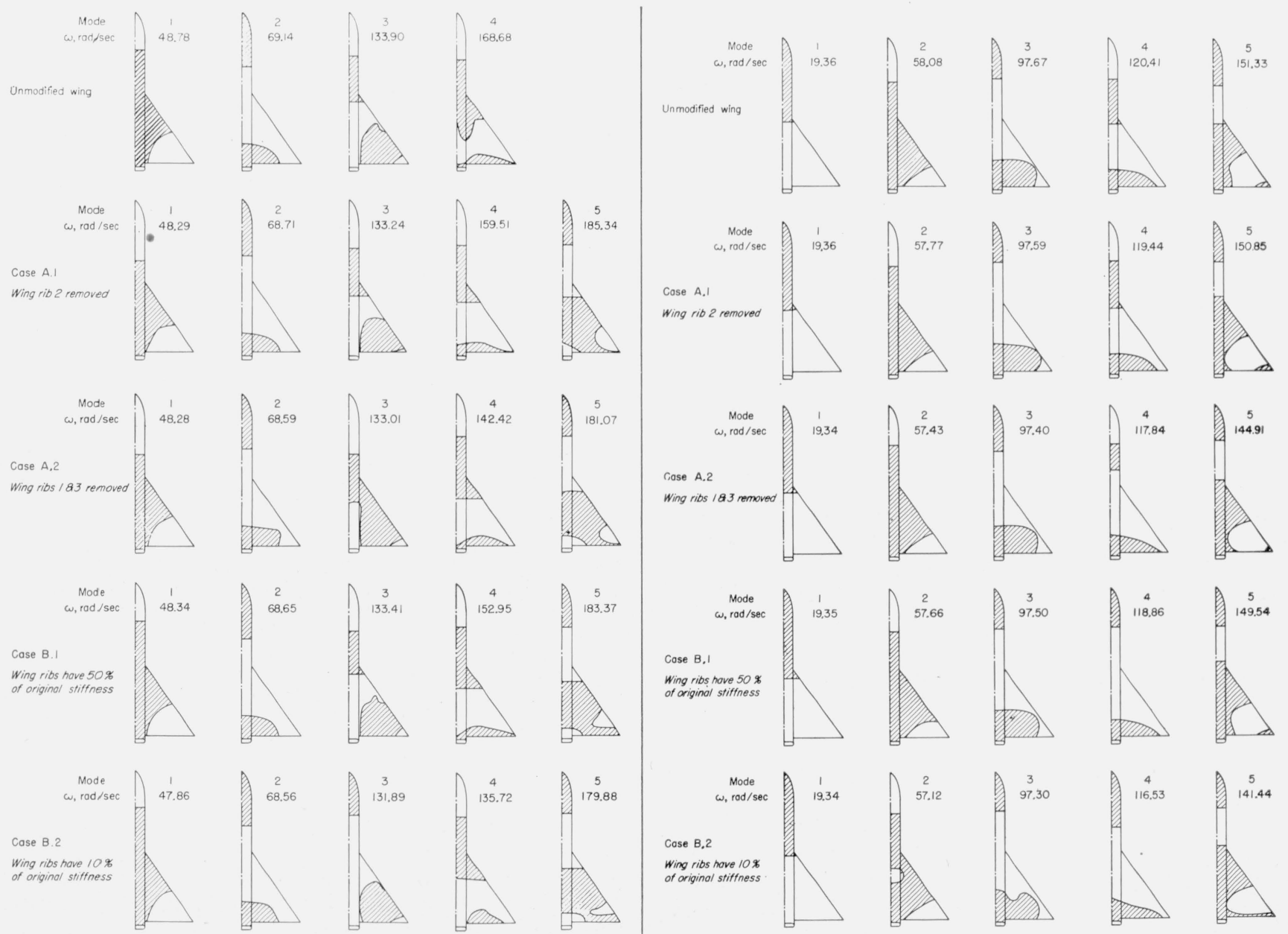

Figure 4. Nodal lines for symmetric modes of vibration.
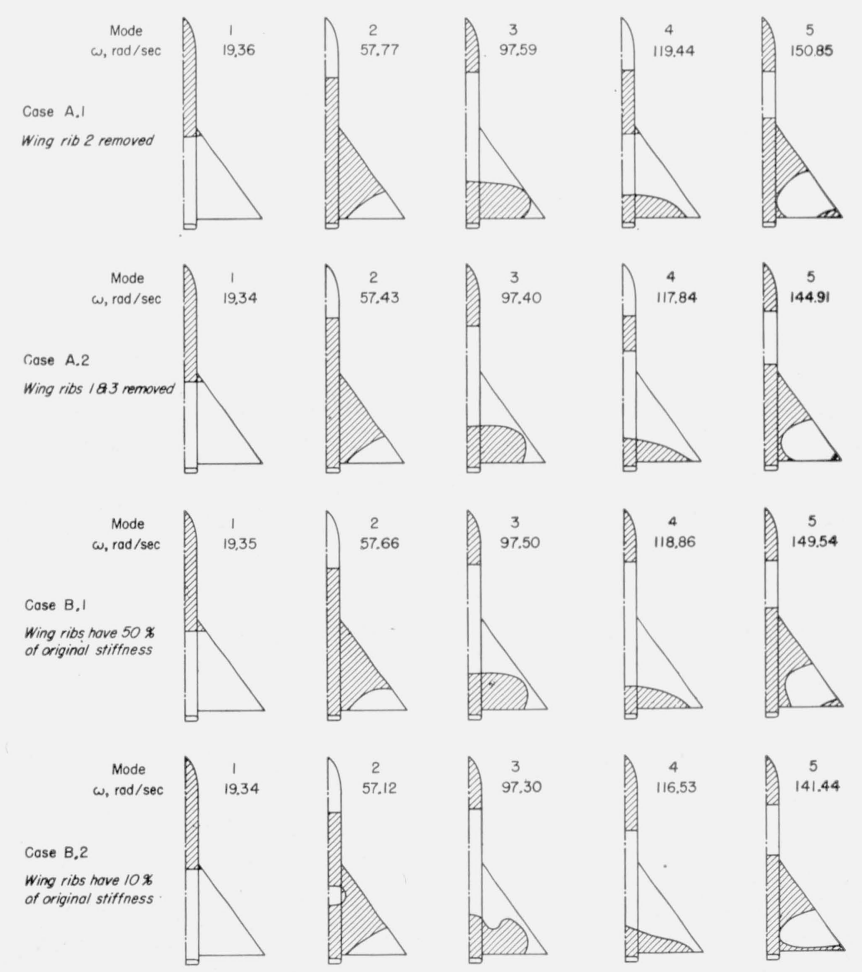

Figure 5. Nodal lines for antisymmetric modes of vibration. 

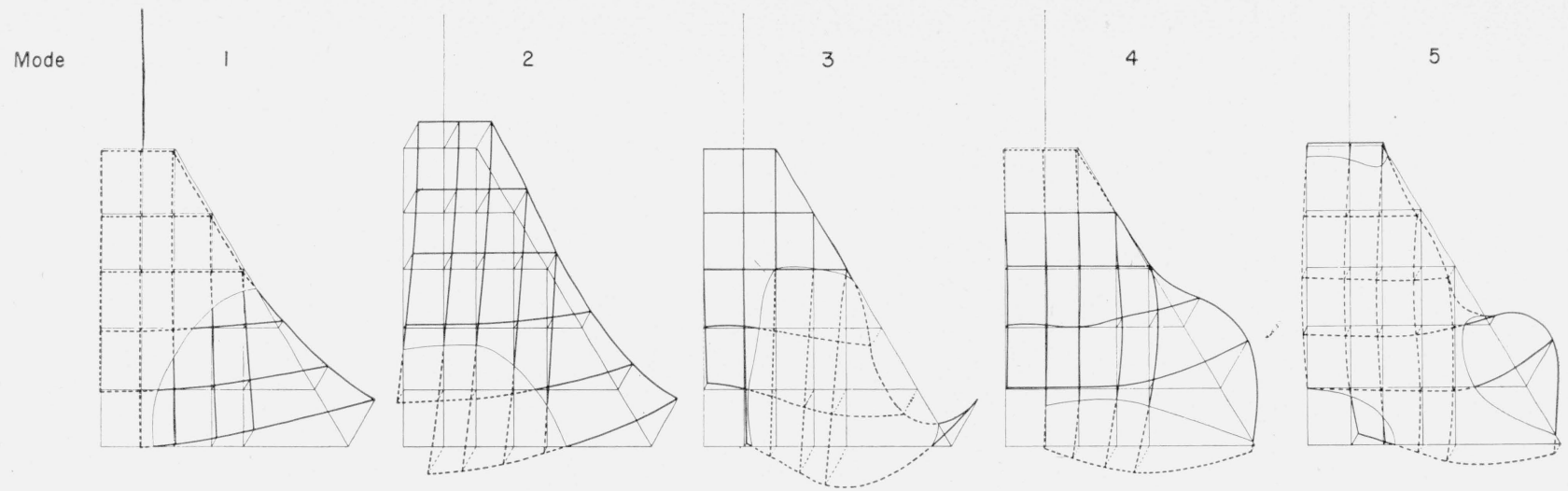

(a) Symmetric modes
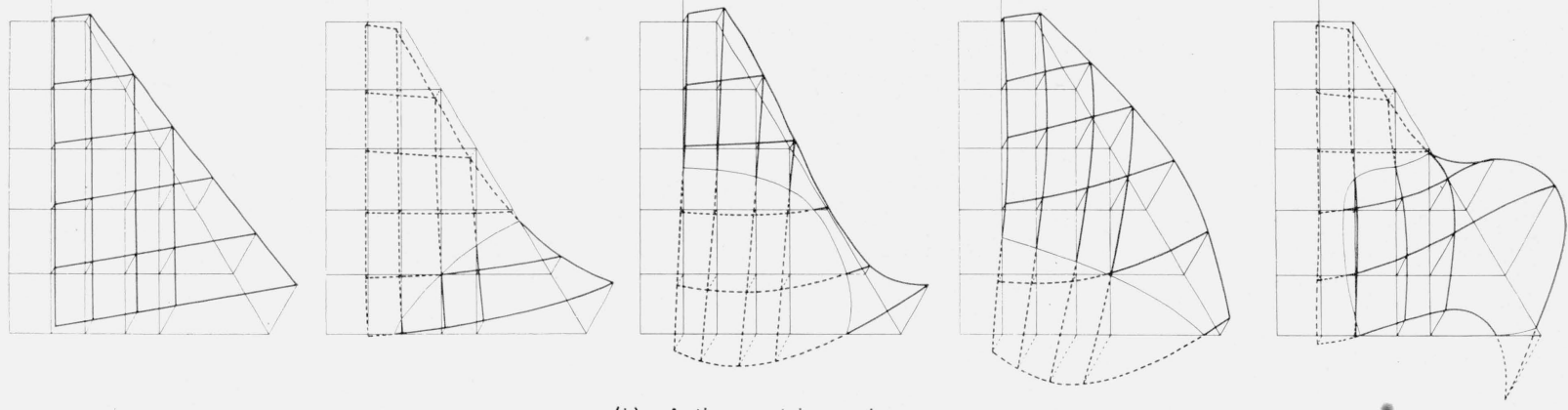

(b) Antisymmetric modes

TABLE 4. Frequencies and normalized deflections of airplone in symmetric modes of vibration for case $B .1$

\begin{tabular}{|c|c|c|c|c|c|}
\hline & $y_{1}$ & $y_{2}$ & $y_{3}$ & $y_{4}$ & $y_{5}$ \\
\hline Station & 48. 338 & 68.646 & 133.406 & 152.951 & 183.370 \\
\hline $\begin{array}{l}61 \\
62 \\
63 \\
64 \\
65\end{array}$ & $\begin{array}{r}-0.023366 \\
.055915 \\
.181575 \\
.353876 \\
1.000000\end{array}$ & $\begin{array}{r}-0.597532 \\
-.522353 \\
-.375947 \\
-.135694 \\
1.000000\end{array}$ & $\begin{array}{r}0.064970 \\
-.221243 \\
-.554459 \\
-. .710990 \\
1.000000\end{array}$ & $\begin{array}{r}-0.039576 \\
-.223265 \\
-.441755 \\
-.585403 \\
-.127819\end{array}$ & $\begin{array}{r}0.244639 \\
.070761 \\
-.166899 \\
-.359846 \\
-.214930\end{array}$ \\
\hline $\begin{array}{l}50 \\
51 \\
52 \\
53 \\
54 \\
55\end{array}$ & $\begin{array}{r}-0.048380 \\
-.029958 \\
.017086 \\
.094203 \\
.203519 \\
.490470\end{array}$ & $\begin{array}{r}-0.273765 \\
-.256161 \\
-.203917 \\
-.106702 \\
.049471 \\
.533566\end{array}$ & $\begin{array}{r}0.119176 \\
.044341 \\
-.137259 \\
-.372036 \\
-.570739 \\
-.539838\end{array}$ & $\begin{array}{r}0.024826 \\
.018315 \\
.016923 \\
.055241 \\
.198112 \\
1.000000\end{array}$ & $\begin{array}{r}-0.007621 \\
-.028416 \\
-.067289 \\
-.068634 \\
.063063 \\
1.000000\end{array}$ \\
\hline $\begin{array}{l}40 \\
41 \\
42 \\
43 \\
44 \\
45\end{array}$ & $\begin{array}{r}-0.041609 \\
-.035294 \\
-.016061 \\
.019798 \\
.076395 \\
.150926\end{array}$ & $\begin{array}{r}0.056758 \\
.066205 \\
.092546 \\
.142327 \\
.224714 \\
.343674\end{array}$ & $\begin{array}{r}0.059669 \\
.027762 \\
-.061488 \\
-.192616 \\
-.329963 \\
-.402425\end{array}$ & $\begin{array}{r}0.035455 \\
.050300 \\
.000034 \\
.205293 \\
.372557 \\
.606766\end{array}$ & $\begin{array}{r}-0.192319 \\
-.207610 \\
-.225663 \\
-.197289 \\
-.067638 \\
.177174\end{array}$ \\
\hline $\begin{array}{l}30 \\
31 \\
32 \\
33 \\
34\end{array}$ & $\begin{array}{r}-0.036457 \\
-.037428 \\
-.037508 \\
-.036011 \\
-.035739\end{array}$ & $\begin{array}{r}0.332393 \\
.332424 \\
.338331 \\
.343156 \\
.335534\end{array}$ & $\begin{array}{r}0.018014 \\
.015574 \\
.002902 \\
-.009667 \\
.011301\end{array}$ & $\begin{array}{r}0.043027 \\
.042329 \\
.053431 \\
.065737 \\
.049961\end{array}$ & $\begin{array}{r}-0.217790 \\
-.231232 \\
-.275082 \\
-.297386 \\
-.232237\end{array}$ \\
\hline $\begin{array}{l}20 \\
21 \\
22 \\
23\end{array}$ & $\begin{array}{r}-0.035268 \\
-.035779 \\
-.036603 \\
-.036025\end{array}$ & $\begin{array}{r}0.498628 \\
.500058 \\
.504975 \\
.502543\end{array}$ & $\begin{array}{r}0.006989 \\
.007170 \\
.007660 \\
.007948\end{array}$ & $\begin{array}{r}0.008233 \\
.007191 \\
.007018 \\
.007373\end{array}$ & $\begin{array}{r}-0.117637 \\
-.121968 \\
-.139345 \\
-.129656\end{array}$ \\
\hline $\begin{array}{l}10 \\
11 \\
12\end{array}$ & $\begin{array}{r}-0.031148 \\
-.030888 \\
-.031025\end{array}$ & $\begin{array}{r}0.582293 \\
.576310 \\
.581933\end{array}$ & $\begin{array}{r}0.000760 \\
.000625 \\
.000666\end{array}$ & $\begin{array}{r}-0.036406 \\
-.036367 \\
-.037373\end{array}$ & $\begin{array}{r}0.050795 \\
.053813 \\
.054991\end{array}$ \\
\hline $\begin{array}{l}02 \\
01\end{array}$ & $\begin{array}{r}-0.003892 \\
.046376\end{array}$ & $\begin{array}{r}0.314251 \\
-.793464\end{array}$ & $\begin{array}{r}-0.007880 \\
.005584\end{array}$ & $\begin{array}{r}-0.103372 \\
.045834\end{array}$ & $\begin{array}{r}0.425884 \\
-.147923\end{array}$ \\
\hline
\end{tabular}

Figure 6. Normalized deflections for case B.1.

TABLE 5. Ratios of frequencies of modified wings to those of basic wing

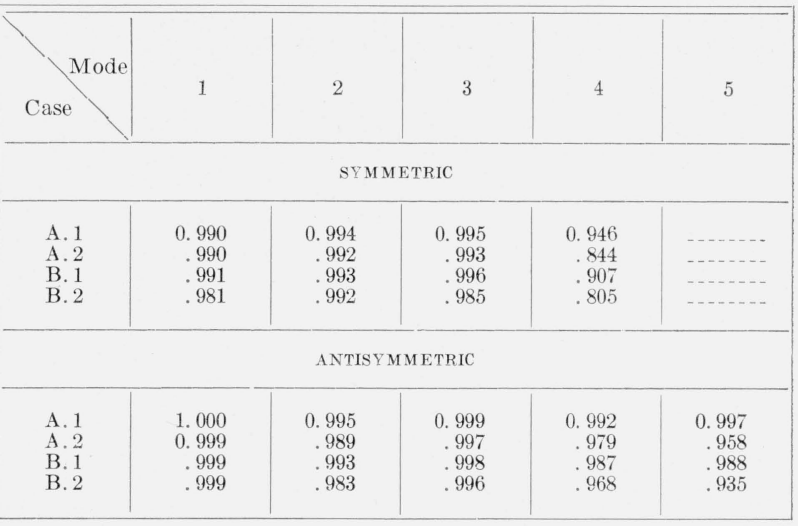

removed, was about 16 percent lower than the frequency for the basic wing. For this same mode, case B.2, wing-rib stiffness 10 percent of basic wingrib stiffness, showed a reduction of about 20 percent. Although the fifth symmetric mode was not computed for the basic wing, the frequencies of the modified wing differ little from each other, table 3 , so it is reasonable to assume that the reduction in frequency is small for this mode also. 
The airplane whose ribs outboard of the fuselage had a stiffness of only 10 percent of the original stiffness, case B.2, showed the greatest reduction in all frequencies, table 5. The airplane with only one of its ribs outboard of the fuselage removed, case A.1, showed the least reduction.

While the modes of vibration differ somewhat, there seems to be little change in the general shape of the vibrations for a particular mode even though the chordwise stiffness of the wing outboard of the fuselage was reduced drastically. This is indicated by the positions of the nodal lines in figures 4 and 5 . However, these graphs do show some regions of local vibration, as for example, in case B.2 antisymmetric where there is a local vibration extending from the fuselage axis a short distance into the wing at station 21. The deflections in these local regions are very small.

Figure 6 shows how the surface of the airplane looks when vibrating in a particular mode. It should be remembered, however, that these are normalized deflections and that the magnitude of the deflections in mode 5, for example, would be much smaller actually than the deflections in mode 1 .

\section{Conclusions}

Based on the results obtained in this study, rib stiffness apparently has little effect on the modes or frequencies of vibration of the delta wing. Modifications of a delta wing similar to those investigated in this paper would not appreciably affect the airplane's vibration characteristics.

No reduction in critical flutter speed as a result of decreased rib stiffness would be indicated from the results.

\section{References}

[1] Leo E. Wilson and Guido E. Ransleben, Jr., The effect of rib flexibility upon flutter characteristics of low aspect ratio wings, Report No. 206c-1 (Southwest Research Inst., Dec. 30, 1952).

[2] Samuel Levy, Structural analysis and influence coefficients for delta wings, J. Aeronaut. Sci. 20, 449 (July 1953).

[3] Samuel Levy, Influence coefficients of tapered cantilever beams computed on SEAC, J. Appl. Mechanics 20, 131 (March 1953).

[4] William F. Cahill and Samuel Levy, Computation of vibration modes and frequencies on SEAC, J. Aeronaut. Sci. 22, 837 (Dec. 1955).

Washington, November 15, 1957. 